\title{
Alterações em atributos do solo decorrentes da aplicação de nitrogênio e palha em sistema semeadura direta na cultura do milho
}

\author{
Changes in soil properties due to application of nitrogen and straw in maize grown under no-till system
}

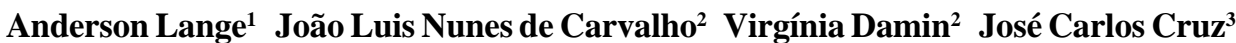 \\ João José Marques ${ }^{4}$
}

\section{RESUMO}

Nos últimos anos, tem-se procurado elevar os teores de $C$ orgânico do solo e, ao mesmo tempo, aumentar a produtividade das culturas. Neste contexto, o sistema semeadura direta (SSD) tem importante participação, principalmente na região dos Cerrados. Entretanto, para se alcançar altas produtividades, as gramíneas requerem a adição de doses elevadas de adubos nitrogenados. Este trabalho teve por objetivo avaliar as alterações no solo decorrentes da aplicação de palha e de $N$ em solo cultivado com milho por 10 anos (1991-2001) em SSD. O experimento foi desenvolvido na Embrapa-Milho e Sorgo, em Sete Lagoas-MG, em um Latossolo Vermelho distrófico típico sob cerrado. Os tratamentos constaram da combinação de palha sobre o solo $(0,3,6,9$ e $12 \mathrm{Mg} \mathrm{ha}^{-1}$ de matéria seca) dispostas nas parcelas, e de cinco níveis de $N$ aplicados em cobertura $\left(0,40,80,120\right.$ e 160kg ha $\left.{ }^{-1}\right)$, na forma de uréia, dispostos nas subparcelas. Foram realizadas duas coletas de solo (antes e após uma calagem), nas profundidades de $0-0,025 ; 0,025-0,05 ; 0,05-0,10 ; 0,10-$ 0,$20 ; 0,20-0,40 m$. Análises químicas e físicas de rotina foram efetuadas usando-se métodos padrões. Os teores de C orgânico $e$ de $\mathrm{K}$ foram influenciados pelas doses de palha e aumentaram à medida que se aumentou a aplicação de palha sobre o solo. A variação nas doses de $\mathrm{N}$ promoveu alterações no $\mathrm{pH}$, nos teores de Ca, Mg e nas saturações por bases e por Al até a profundidade de $0,20 \mathrm{~m}$. A calagem superficial promoveu o aumento do $\mathrm{pH}$ do solo em profundidade e dos teores de Ca, até $0,20 \mathrm{~m}$, provavelmente devido à alta pluviosidade no período pós-calagem (1600mm em oito meses).

Palavras-chave: calagem superficial; adubação nitrogenada; Latossolo; Cerrados.

\section{ABSTRACT}

Agricultural practices have been trying to increase the content of organic $C$ in soils and at the same time to increase yields. In this context, the no-till system (NTS) has an important role to play, particularly in the Cerrado region of Brazil. However, to reach high yields, the crops demand high inputs of $N$ fertilizers. The objective of this work was to evaluate the modifications induced in the soil after ten years (1991-2001) of NTS, influenced by different straw and $N$ doses. The experiment was set at the Embrapa farm in Sete Lagoas-MG, on a typic Dystrofic Red Latosol under Cerrado vegetation. The treatments consisted of five straw doses $\left(0,3,6,9\right.$ e $12 \mathrm{Mg} \mathrm{ha}^{-1}$ of dry matter) in the plot and five doses of $N(0,40,80,120$ e $160 \mathrm{~kg}$ $h a^{-1}$ ) as urea in the subplot. Two samplings were accomplished, before and after liming. The soil layers sampled were 0-0.025; $0.025-0.05 ; 0.05-0.10 ; 0.10-0.20$; and 0.20-0.40m. Routine soil physical and chemical variables were measured according to standard procedures. The contents of organic $C$ and $K$ were influenced by the different straw doses and increased as the application of straw increased. The different doses of $N$ influenced $\mathrm{pH}, \mathrm{Ca}, \mathrm{Mg}, \mathrm{Al}$, base and Al saturation, up to $0.20 \mathrm{~m}$. The surface liming was capable of increasing $\mathrm{pH}$, in some cases up to $0.20 \mathrm{~m}$, and the same happened for Ca. The vertical movement of the lime in the profile was probably due to the good physical properties of the soil and to the heavy rainfall (1600mm in eight months).

Key words: surface liming; nitrogen amendment; Latosol.

\section{INTRODUÇÃO}

A região dos Cerrados ocupa posição de destaque no contexto agrícola brasileiro, por apresentar diversas características desejáveis à produção de grãos. Tem se observado um grande desenvolvimento da agricultura na região, onde muitos produtores adotam tecnologia aliada a métodos adequados de manejo,

${ }^{1}$ Centro de Energia Nuclear na Agricultura-Universidade de São Paulo (USP), Piracicaba, SP, Brasil.

${ }^{2}$ Escola Superior de Agricultura Luiz de Queiroz (ESALQ), USP, Piracicaba, SP, Brasil.

${ }^{3}$ Embrapa-Milho e Sorgo, Sete Lagoas, MG, Brasil.

${ }^{4}$ Departamento de Ciência do Solo, Universidade Federal de Lavras, (UFLA), Cp. 3037, 37200-000, Lavras, MG, Brasil. E- mail: jmarques@ufla.br. Autor para correspondência. 
refletindo em aumento significativo de produtividade. O sistema semeadura direta (SSD) muito tem contribuído para esse cenário.

O SSD trouxe como conseqüência modificações nos atributos físicos e químicos do solo. Entre essas, destaca-se o aumento nos teores de $\mathrm{C}$ orgânico (CO) do solo, supostamente devido à manutenção da palha na superfície, além de diversos outros benefícios (BAYER \& BERTOL, 1999; SÁ, 1999; BEUTLER et al., 2001). Segundo CAMPOS et al. (1995), à medida que se adiciona $\mathrm{CO}$ ao solo, a atividade microbiana é estimulada, resultando em produtos que atuam na formação e estabilização dos agregados. Além disso, diversos trabalhos têm demonstrado que o SSD aumenta a concentração de nutrientes na superfície do solo(MUZILLI, 1983; SIDIRAS \& PAVAN, 1985; BAYER \& BERTOL, 1999; SÁ, 1999).

Entre os nutrientes requeridos pelas culturas, o N é o mais exigido, superando em quantidade P e K. Entretanto, a aplicação de altas doses de adubos nitrogenados, principalmente amoniacais, traz como conseqüência a acidificação do solo. SÁ (1999) observou queda de $\mathrm{pH}$ do solo após cultivo da seqüência milho-trigo. Segundo o autor, a adição de $190 \mathrm{~kg} \mathrm{~N} \mathrm{Na}^{-1}$ teria provocado acidificação no solo. O mesmo foi observado por MUZILLI (1983) e FRANCHINI et al. (2000) em seqüências de culturas que requeriam altas doses de N. BLEVINS et al. (1977) e STALEY \& BOYER (1997) documentam também a redução do pH do solo em função da aplicação de $\mathrm{N}$.

A fertilização com uréia, por ser uma molécula de reação básica, inicialmente causa um aumento do $\mathrm{pH}$, principalmente ao redor dos grânulos do adubo. Porém, após nitrificação do amônio, o pH decresce para valores inferiores aos originais. A acidificação provocada pelo uso de adubos nitrogenados pode alterar também outros atributos químicos do solo, com aumento do teor de Al trocável, redução da CTC efetiva e das bases trocáveis (PAIVA, 1990) e, conseqüentemente, aumentar a necessidade de calagem.

Para contornar esse problema, é realizada, em SSD, a calagem na superfície do solo. Tem sido observada movimentação de calcário no perfil do solo, e tal movimentação é dependente das características e das condições de cada local, podendo ocorrer por meio de canais resultantes da decomposição de raízes de culturas antecedentes, da maior atividade da macrofauna, da estrutura e textura do solo e da pluviometria (CAIRES et al., 1998; POTTKER \& BEN, 1998). Entretanto, para as condições dos Cerrados, poucos estudos foram desenvolvidos até o momento para avaliar esse efeito.

Este trabalho teve por objetivo avaliar as alterações de alguns atributos físicos e químicos em solo cultivado com milho em sistema semeadura direta há dez anos, em função da aplicação de palha e de N, antes e após calagem superficial.

\section{MATERIAL E MÉTODOS}

O trabalho foi desenvolvido em área experimental da Embrapa-Milho e Sorgo em Sete Lagoas-MG ao redor do ponto 44¹0'59” W e 19²7'21" S, a 790m de altitude, em um Latossolo Vermelho distrófico típico, representativo da região dos Cerrados.

Os tratamentos constaram da combinação de palha de milho sobre o solo (ausência de palha, 3, 6, 9 e $12 \mathrm{Mg} \mathrm{ha}^{-1}$ de matéria seca) dispostas nas parcelas, e de cinco níveis de $\mathrm{N}$ aplicados em cobertura no milho (ausência de N, 40, 80, 120 e 160 $\mathrm{kg} \mathrm{ha}^{-1}$ ), na forma de uréia, dispostos nas subparcelas. Estes tratamentos foram delineados em blocos ao acaso com três repetições. As dimensões das parcelas foram 21,0x14,4m e das subparcelas 7,0x7,2m. A área do experimento vinha, há dez anos, desde 1991, sendo cultivada com milho em SSD, segundo os tratamentos descritos acima. A resteva de cada safra era deixada sobre o solo. Adicionalmente, palha de milho, trazida de outras áreas, era anualmente aplicada na superfície do solo, cerca de 20 dias antes da semeadura do milho, de modo a simular a quantidade de palha oriunda de plantas de cobertura.

A utilização de palha de milho, apesar de não representar a realidade de uma planta de cobertura, deveu-se à abundante disponibilidade da mesma ao longo dos anos. A aplicação de palha oriunda de outras áreas, apesar de não expressar o manejo típico do SSD, foi a forma utilizada para garantir o aporte anual fixo de palha ao longo do período experimental, permitindo a quantificação de seu efeito no solo. De outra forma, seria impossível quantificar isoladamente o efeito da palha sobre o solo.

A fonte de $\mathrm{N}$ foi a uréia, aplicada em superfície, próximo à linha de semeadura, no estádio de seis a sete folhas desenvolvidas. Ao longo do experimento, a adubação básica foi de $300 \mathrm{~kg} \mathrm{ha}^{-1}$ de NPK + Zn na fórmula 5-20-20 + 0,5\% . 
Amostragens de solo para acompanhamento de atributos químicos foram realizadas em duas épocas. A primeira, realizada em maio de 2001 (após a colheita do milho), teve por objetivo avaliar o efeito das doses de palha e de $\mathrm{N}$ no solo. Para tanto, foram abertas minitrincheiras $(0,6 \times 0,5 \times 0,5 \mathrm{~m})$ perpendicularmente à linha de semeadura, coletando-se amostras nas profundidades $0-0,025 ; 0,025-0,05 ; 0,05-0,10 ; 0,10$ 0,$20 ; 0,20-0,40 \mathrm{~m}$, na linha e na entrelinha de semeadura. Coletaram-se também amostras nas profundidades 0 0,05; 0,05-0,10 e 0,10-0,15m, com auxílio de anéis de Kopecky para determinação da densidade do solo (DS). Foi ainda determinada a estabilidade de agregados em água, na profundidade $0-0,025 \mathrm{~m}$, de onde se calculou o diâmetro médio geométrico (DMG).

Com base nos resultados médios da profundidade $0-0,20 \mathrm{~m}$ de todos os tratamentos, calculou-se a necessidade de calagem pelo método da saturação por bases para elevá-la a 60\%. Como em SSD a aplicação de calcário é feita superficialmente, é recomendada a redução da dose a ser aplicada para cerca de 30\% do calculado (LOPES, 1999). Assim, em setembro/2001, aplicou-se $0,5 \mathrm{Mg} \mathrm{ha}^{-1}$ de calcário calcítico, PRNT 80\%, em área total.

A segunda amostragem de solo foi realizada em maio de 2002, após a colheita do milho da safra 2001/02, obedecendo ao mesmo procedimento da primeira amostragem, omitindo-se, porém, a profundidade $0,20-0,40 \mathrm{~m}$. As análises físicas e químicas de solo realizadas seguiram os métodos padrão descritos em EMBRAPA(1997) e SILVA(1999).

Os resultados obtidos foram submetidos à análise de regressão polinomial, considerando-se o efeito das doses de palha e de $\mathrm{N}$ nas diferentes profundidades. Adicionalmente, aplicou-se o teste de Scott-Knott a 5\% de probabilidade, para a comparação de médias de cada profundidade, considerando-se as duas épocas de amostragem. Quando não houve interação entre os fatores, foram apresentadas e discutidas somente as médias dos efeitos principais.

\section{RESULTADOS E DISCUSSÃO}

Provavelmente devido ao alto teor de CO (Figura 1) em todas as parcelas e subparcelas, não houve efeito dos tratamentos sobre nenhum dos atributos físicos do solo avaliados. Os valores dos atributos físicos avaliados foram semelhantes aos encontrados por CAMPOS et al. (1995) e BEUTLER et al. (2001). Por esse motivo, os resultados dos atributos físicos não serão discutidos neste trabalho.

O efeito da aplicação de palha foi verificado para os teores de CO apenas na profundidade de 0$0,025 \mathrm{~m}$ e nos de $\mathrm{K}$ até a profundidade de $0,20 \mathrm{~m}$, sendo que ambos aumentaram conforme se elevou a quantidade de palha aplicada (Figura 1). Explica-se o aumento dos teores de K pela aplicação de palha pelo fato de a mesma conter quantidades altas desse nutriente (FANCELLI \& DOURADO NETO, 2000). Os valores médios de $\mathrm{CO}$ encontrados nos diferentes tratamentos variaram de $25 \mathrm{~g} \mathrm{~kg}^{-1}(0-0,025 \mathrm{~m})$ a $18 \mathrm{~g} \mathrm{~kg}^{-1}$ $(0,20-0,40 \mathrm{~m})$ para as diferentes profundidades. No Paraná, CASTRO FILHO et al. (1998), ao estudarem o efeito de três diferentes sistemas de rotação durante 14 anos, não observaram diferenças nos estoques de CO no solo. BAYER \& BERTOL (1999) observaram, na região Sul do Brasil, que os teores de CO num Cambissolo Húmico variam de $43-27 \mathrm{~g} \mathrm{~kg}^{-1}$ para a profundidade $0-0,20 \mathrm{~m}$, evidenciando a influência da classe de solo sobre o potencial de acúmulo de CO.

Mesmo tendo sido observada diferença no teor de CO na profundidade de $0-0,025 \mathrm{~m}$, a variação foi mínima, 24 e $27 \mathrm{~g} \mathrm{CO} \mathrm{kg}{ }^{-1}$ para os tratamentos 0 e $12 \mathrm{Mg} \mathrm{ha}^{-1}$ ano $^{-1}$ de palha aplicada. Esses resultados, em parte, podem ser atribuídos ao fato de a palha aportada ao sistema ser proveniente de adição externa, não havendo crescimento de cultura de inverno na área, indicando que o aumento do teor de CO do solo normalmente verificado em SSD se deve não somente à palha oriunda da parte aérea das culturas, mas também, e talvez principalmente, ao sistema radicular destas. Ademais, as variações no teor de CO ao longo de perfil também foram pequenas, sendo os valores na profundidade de $0,20-0,40 \mathrm{~m}$ próximos aos encontrados em cerrado nativo $\left(20 \mathrm{~g} \mathrm{~kg}^{-1}\right)$ no mesmo local (BEUTLER et al., 2001). Este fato mostra o restabelecimento gradativo do teor de CO do solo pela adoção do SSD.

Os valores médios de $\mathrm{pH}$ encontrados variaram de 5,3, na profundidade $0-0,025 \mathrm{~m}$, a 4,9, na profundidade $0,20-0,40 \mathrm{~m}$. A aplicação de $\mathrm{N}$ em cobertura, ocasionou um decréscimo significativo no pH do solo em subsuperfície, até 0,20m (Figura 1). SÁ 


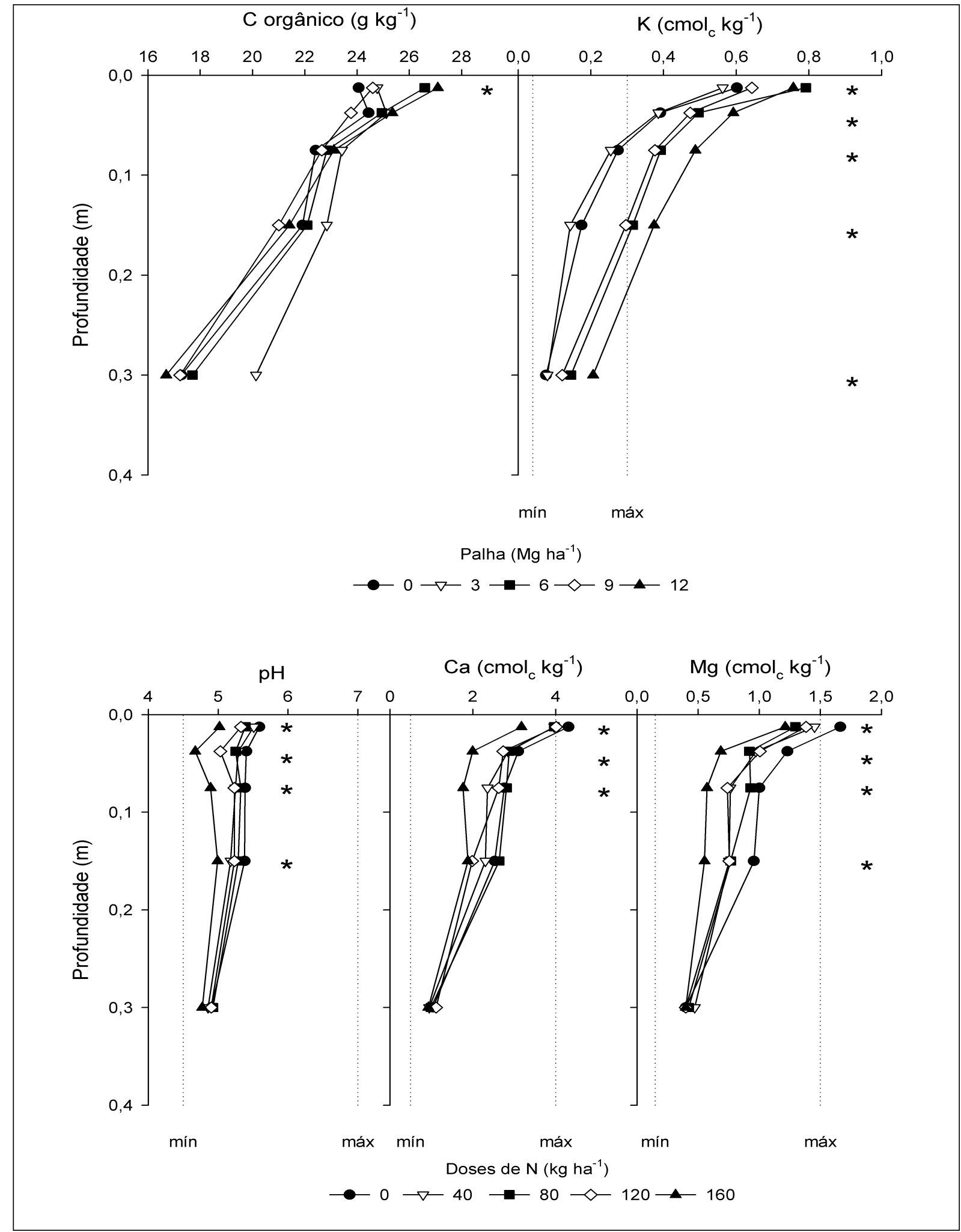

Figura 1 - Influência de doses de palha e de nitrogênio em sistema de semeadura direta na cultura do milho sobre o teor de C orgânico, $\mathrm{K}$ (a), pH do solo e teores de Ca e de Mg (b) de um Latossolo Vermelho Distrófico típico do Cerrado, em diferentes profundidades $(*=$ significativo a $5 \%) . \mathrm{n}=15$. Linhas tracejadas indicam classes de interpretação de fertilidade do solo $(<$ mín = muito baixo e >máx = muito alto) (ALVAREZ et al., 1999). 
(1999), em experimentos de calagem superficial em SSD, observou que, em áreas cultivadas com milho, houve tendência de redução do $\mathrm{pH}$ do solo ao longo dos anos, demonstrando a ação acidificante dos fertilizantes nitrogenados. BLEVINS et al. (1977) e STALEY \& BOYER (1997) também relatam redução do $\mathrm{pH}$ do solo até $0,15 \mathrm{~m}$ de profundidade devida à aplicação de $\mathrm{N}$, em áreas cultivadas em SSD. Ainda, comparativamente ao sistema de preparo convencional, o pH do solo sob SSDémaior(MUZILLI, 1983; SIDIRAS \& PAVAN, 1985).

Os resultados da figura 1 demonstram que a acidificação do solo provocada por adubos nitrogenados não se restringe à camada superficial, mas afeta também a subsuperfície. Todos os tratamentos que receberam adubação nitrogenada em cobertura apresentaram $\mathrm{pH}<5,4$ até $0,20 \mathrm{~m}$ de profundidade. Tal valor de $\mathrm{pH}$ é considerado baixo (ALVAREZ et al., 1999).

Os teores médios de Ca observados variaram de $3,9 \mathrm{cmol}_{\mathrm{c}} \mathrm{kg}^{-1}(0-0,025 \mathrm{~m})$ a $1,0 \mathrm{cmol}_{\mathrm{c}} \mathrm{kg}^{-1}$ $(0,20-0,40 \mathrm{~m})$ e os teores médios de $\mathrm{Mg}$ de $1,4 \mathrm{cmol}_{\mathrm{c}} \mathrm{kg}^{-1}$ (0-0,025m) a $0,4 \mathrm{cmol}_{\mathrm{c}} \mathrm{kg}^{-1}(0,20-0,40 \mathrm{~m})$. A variação na dose de $\mathrm{N}$ influenciou significativamente os teores de Ca até $0,1 \mathrm{~m}$ e os de $\mathrm{Mg}$ até $0,20 \mathrm{~m}$ de profundidade (Figura 1). Os menores valores de Ca e Mg trocáveis foram observados quando da aplicação de doses mais altas de $\mathrm{N}$, também refletindo a acidificação provocada pela adubação nitrogenada. Segundo PAVAN \& OLIVEIRA (1997), a aplicação de fertilizantes amoniacais causa acidificação do solo e faz com que parte das cargas do solo sejam ocupadas pelo $\mathrm{Al}$, impedindo a adsorção de cátions básicos. Assim, os cátions básicos tornam-se mais facilmente lixiviados, resultando em menores teores de Ca e Mg nas maiores doses de $\mathrm{N}$ aplicadas. À semelhança do $\mathrm{pH}$ do solo, a camada mais subsuperficial $(0,20-0,40 \mathrm{~m})$ não foi influenciada pela aplicação de $\mathrm{N}$, independentemente da dose, apresentando teores médios de Ca iguais a 1,0 e de $\mathrm{Mg}$ iguais a $0,4 \mathrm{cmol}_{\mathrm{c}} \mathrm{kg}^{-1}$, os quais são considerados baixos (ALVAREZ et al., 1999). FRANCHINI et al. (2000) observaram redução nos teores de $\mathrm{Mg}$ do solo, na camada de $0-0,10 \mathrm{~m}$, quando cultivaram espécies exigentes em $\mathrm{N}$.

O comportamento observado para os valores de Al trocável e de saturação por Al foi semelhante. Por essa razão, é apresentada apenas a saturação por Al. Os valores de saturação por Al variaram de 6 a 47\% para as diferentes profundidades (Figura 2). As doses de $\mathrm{N}$ afetaram significativamente os valores de saturação por Al até $0,20 \mathrm{~m}$ de profundidade, aumentando proporcionalmente às doses de $\mathrm{N}$, o que reflete a acidificação do solo oriunda da adubação nitrogenada. À semelhança de outros atributos já discutidos, não se observou tendência de modificação destes na profundidade de 0,20-0,40m.

A aplicação de $\mathrm{N}$ influenciou também a saturação por bases do solo até a profundidade $0,20 \mathrm{~m}$ (Figura 2). Comparando-se os valores extremos, 0 e $160 \mathrm{~kg} \mathrm{~N} \mathrm{ha}^{-1}$, observa-se redução de $20 \%$, em média, da saturação por bases entre os dois tratamentos. Esse efeito é atribuído à elevada dose de $\mathrm{N}$ aplicada. PAIVA (1990) também observou que a aplicação anual de 90kg $\mathrm{N} \mathrm{a}^{-1}$, como sulfato de amônio, reduziu em cerca de $20 \%$ a saturação por bases do solo após sete anos de cultivo de milho em SSD. O valor médio da saturação por bases para todos os tratamentos até $0,20 \mathrm{~m}$ de profundidade foi de aproximadamente $40 \%$, evidenciando que, após 10 anos de SSD, há a necessidade real de correção da acidez do solo, o que também se verificou pelos baixos valores de soma de bases, aparente deficiência de Ca no solo e pH baixo.

\section{Efeitos da calagem}

Os efeitos verificados na primeira amostragem repetiram-se na segunda, para praticamente todos os atributos químicos avaliados, confirmando os resultados da primeira amostragem e conferindo confiabilidade ao método de amostragem de solo adotado. A variação nas doses de $\mathrm{N}$ influenciou significativamente o $\mathrm{pH}$ do solo até a profundidade $0,20 \mathrm{~m}$, com comportamento semelhante ao da amostragem anterior. Menores valores de $\mathrm{pH}$ foram observados quando da aplicação das maiores doses de N. Entretanto, a aplicação superficial de calcário promoveu elevação do pH do solo (Tabela 1).

Ao considerar-se exclusivamente o efeito da época de amostragem, antes e após a calagem, observa-se que, após a correção do solo, maiores valores de $\mathrm{pH}$ foram encontrados em todas as profundidades avaliadas. As diferenças, contudo, foram pequenas do ponto de vista prático, possivelmente em virtude da pequena dose de calcário recomendada e aplicada. Porém, a aplicação de calcário modificou significativamente o pH do solo para além da superfície 


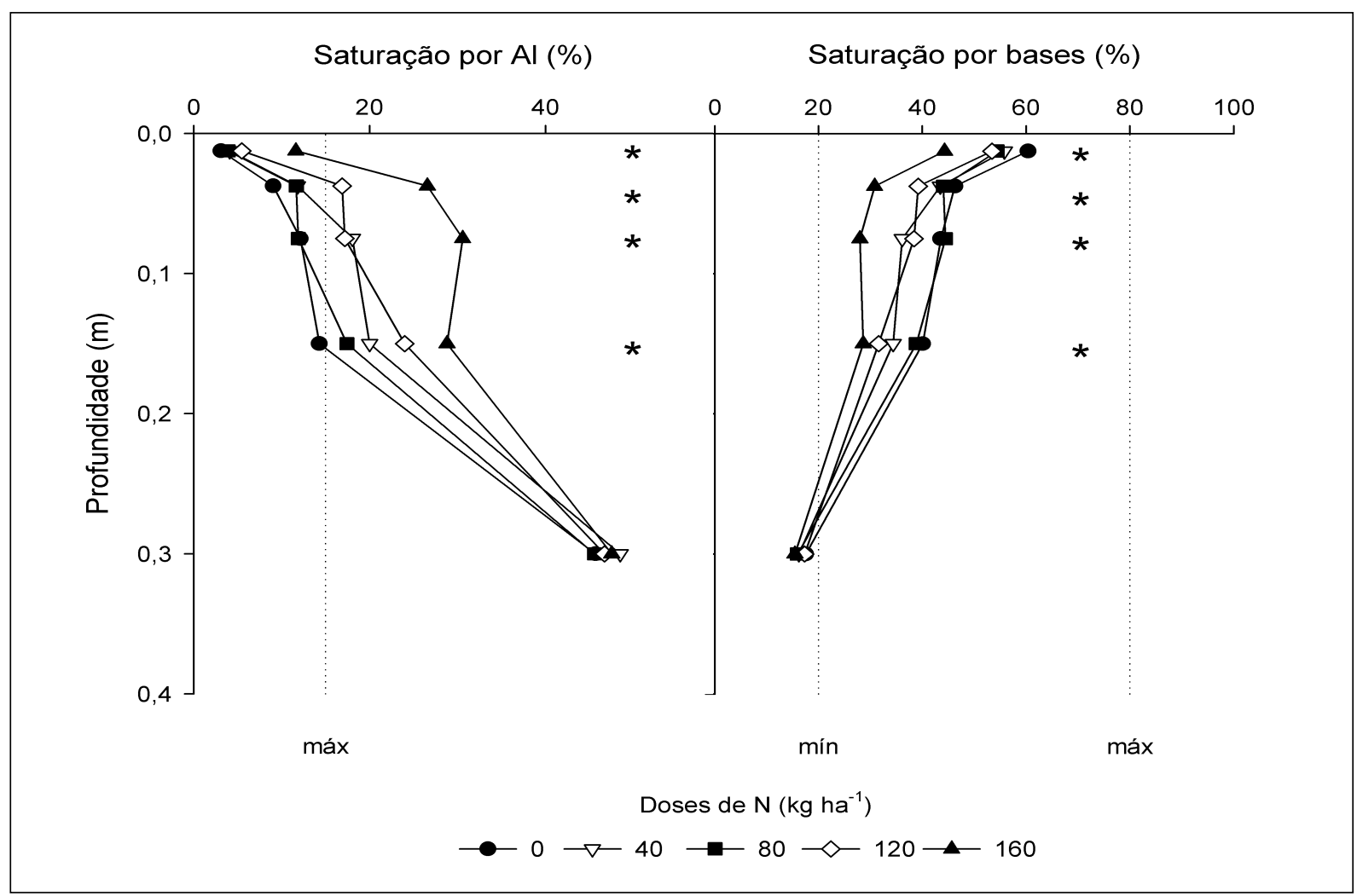

Figura 2 - Influência de doses de N em Sistema de Semeadura Direta na cultura do milho sobre a saturação de bases e saturação de alumínio de um Latossolo Vermelho Distrófico típico do Cerrado em diferentes profundidades. (* = significativo a 5\%). n=15. Linhas tracejadas indicam classes de interpretação de fertilidade do solo (mín = mínimo e máx = máximo), conforme ALVAREZ et al. (1999).

do solo (0-0,05m), com elevação de 4,7 para 5,2. Este resultado demonstra que, mesmo a aplicação de uma baixa quantidade de calcário, $0,5 \mathrm{Mg} \mathrm{ha}^{-1}$, em superfície em SSD já estabelecido apresenta efeito corretivo, embora modesto, da acidez até $0,20 \mathrm{~m}$.

A movimentação vertical de calcário também foi detectada por SÁ (1999), o qual observou um aumento significativo do $\mathrm{pH}$ na profundidade 0,025 0,05m no primeiro ano após a aplicação de calcário, tendo detectado efeito semelhante até a profundidade de $0,10 \mathrm{~m}$ no terceiro ano de aplicação. Nesse estudo, o $\mathrm{pH}$ do solo era muito baixo, próximo a 4,0, e foram realizados dois cultivos por ano, requerendo doses elevadas de $\mathrm{N}$, o que pode ter minimizado o efeito inicial da calagem, em relação aos dados deste experimento.

As doses de $\mathrm{N}$ também influenciaram os teores de Ca no perfil do solo até a profundidade de $0,10 \mathrm{~m}$, repetindo comportamento descrito para a amostragem anterior à calagem. A aplicação superficial de calcário aumentou os teores médios de Ca no solo até a profundidade $0,20 \mathrm{~m}$, quando comparados aos valores anteriores à calagem (Tabela 1 ). $\mathrm{O}$ aumento no teor de Ca não foi acentuado em virtude da pequena quantidade de calcário aplicada. Possivelmente, a dose de calcário aplicada, calculada conforme LOPES (1999), subestimou as reais necessidades de Ca do solo. Aumento nos teores de Ca foram observados também por CAIRES et al. (1998), POTTKER \& BEN (1998). Estes autores verificaram maiores efeitos, porém, também utilizaram maiores doses de calcário.

O movimento de Ca não se restringiu à camada superficial de solo, havendo migração e aumento do teor do nutriente para camadas inferiores. Segundo SUMNER \& PAVAN (2000), existe no solo uma frente de correção da acidez, ou seja, movimentação de íons $\mathrm{HCO}_{3}^{-}$e $\mathrm{OH}^{-}$, através de fluxo de massa. Esses ânions possibilitariam, também, a movimentação de Ca e outros cátions básicos. Os resultados deste trabalho confirmam a existência de uma frente de correção da acidez e de aumento nos 
Tabela 1 - Variações de pH e Ca no perfil de um Latossolo Vermelho distrófico típico do Cerrado, antes e após a calagem, para diferentes doses de N aplicadas em cobertura na cultura do milho em Sistema de Semeadura Direta.

\begin{tabular}{|c|c|c|c|c|c|c|c|c|}
\hline \multirow{3}{*}{$\mathrm{N}\left(\mathrm{kg} \mathrm{ha}^{-1}\right)$} & \multicolumn{8}{|c|}{ Profundidades (m) } \\
\hline & \multicolumn{2}{|c|}{$0-0,025$} & \multicolumn{2}{|c|}{$0,025-0,05$} & \multicolumn{2}{|c|}{$0,05-0,10$} & \multicolumn{2}{|c|}{$0,10-0,20$} \\
\hline & Antes & Após & Antes & Após & Antes & Após & Antes & Após \\
\hline & \multicolumn{8}{|c|}{$\mathrm{pH}$ do solo } \\
\hline 0 & 5,59 a & 5,73 a & 5,40 a & $5,70 \mathrm{~b}$ & 5,39 a & $5,65 \mathrm{~b}$ & 5,38 a & 5,57 a \\
\hline 40 & 5,51 a & 5,51 a & 5,28 a & 5,47 a & 5,25 a & $5,42 \mathrm{a}$ & 5,18 a & 5,41 a \\
\hline 80 & 5,39 a & 5,50 a & 5,25 a & 5,47 a & 5,32 a & 5,33 a & 5,29 a & 5,35 a \\
\hline 120 & $5,32 \mathrm{a}$ & $5,40 \mathrm{a}$ & $5,03 \mathrm{a}$ & $5,30 \mathrm{a}$ & $5,23 \mathrm{a}$ & $5,34 \mathrm{a}$ & 5,23 a & $5,49 \mathrm{~b}$ \\
\hline 160 & $5,02 \mathrm{a}$ & $5,30 \mathrm{~b}$ & 4,67 a & $5,18 \mathrm{~b}$ & $4,90 \mathrm{a}$ & $5,05 \mathrm{a}$ & 4,99 a & $5,15 \mathrm{a}$ \\
\hline Média & 5,36 a & $5,49 \mathrm{~b}$ & 5,13 a & $5,42 \mathrm{~b}$ & $5,22 \mathrm{a}$ & $5,36 \mathrm{~b}$ & $5,21 \mathrm{a}$ & $5,40 \mathrm{~b}$ \\
\hline \multirow[t]{2}{*}{ CV (\%) } & \multicolumn{2}{|c|}{4,6} & \multicolumn{2}{|c|}{7,2} & \multicolumn{2}{|c|}{5,8} & \multicolumn{2}{|c|}{6,1} \\
\hline & \multicolumn{8}{|c|}{ Ca no solo $\left(\mathrm{cmol}_{\mathrm{c}} \mathrm{kg}^{-1}\right)$} \\
\hline 0 & 4,3 a & $5,1 \mathrm{~b}$ & 3,1 a & 4,1 b & $2,8 \mathrm{a}$ & $3,9 \mathrm{~b}$ & $2,5 \mathrm{a}$ & $3,4 \mathrm{~b}$ \\
\hline 40 & $4,0 \mathrm{a}$ & $4,7 \mathrm{~b}$ & $2,8 \mathrm{a}$ & $3,7 \mathrm{~b}$ & $2,3 \mathrm{a}$ & $3,2 \mathrm{~b}$ & $2,3 \mathrm{a}$ & $3,2 \mathrm{~b}$ \\
\hline 80 & $4,0 \mathrm{a}$ & $4,7 \mathrm{~b}$ & 2,9 a & $3,6 \mathrm{~b}$ & 2,8 a & 3,1 a & 2,6 a & 3,0 a \\
\hline 120 & $4,0 \mathrm{a}$ & 4,4 a & 2,7 a & $3,5 b$ & 2,6 a & 3,1 a & $2,0 \mathrm{a}$ & $3,2 \mathrm{~b}$ \\
\hline 160 & $3,2 \mathrm{a}$ & $4,1 \mathrm{~b}$ & $2,0 \mathrm{a}$ & $3,1 \mathrm{~b}$ & $1,8 \mathrm{a}$ & $2,4 \mathrm{a}$ & $1,9 \mathrm{a}$ & $2,4 \mathrm{a}$ \\
\hline Média & 3,8 a & $4,6 \mathrm{~b}$ & 2,7 a & $3,6 \mathrm{~b}$ & $2,4 \mathrm{a}$ & $3,2 \mathrm{~b}$ & 2,3 a & $3,0 \mathrm{~b}$ \\
\hline CV (\%) & \multicolumn{2}{|c|}{17,1} & \multicolumn{2}{|c|}{27,7} & \multicolumn{2}{|c|}{32,9} & \multicolumn{2}{|c|}{37,2} \\
\hline
\end{tabular}

Letras na linha comparam valores antes e após a calagem para cada mesma profundidade (5\% de probabilidade).

teores de Ca no solo após a aplicação de calcário em superfície, sendo esta frente proporcional à dose de calcário aplicada, às condições de acidez e ao teor de Ca do solo. Evidencia-se, ainda, que as ótimas condições físicas do solo e a elevada precipitação que ocorreu no período (1600mm em oito meses), otimizaram o efeito do calcário na correção da acidez subsuperficial. Alguns autores têm atribuído a movimentação de Ca no perfil do solo à formação de pares com compostos orgânicos provenientes de adubos verdes (MIYAZAWA et al., 1996; FRANCHINI et al., 2001). Apesar desse não ter sido objetivo específico deste trabalho, a aplicação de diferentes doses de palha em superfície parece não ter influenciado a movimentação de Ca no perfil do solo. Esperar-se-ia um efeito positivo da aplicação de palha na movimentação de íons, já que esta deve ter liberado alguns compostos orgânicos durante sua decomposição. Contudo, tal efeito não foi verificado. Logo, parece mais provável que a movimentação de íons do calcário tenha sido devida às boas condições físicas do solo e às elevadas precipitações que ocorreram durante o período.

\section{CONCLUSÕES}

A adição anual de doses elevadas de palha de milho, até $12 \mathrm{Mg} \mathrm{ha}^{-1}$, durante longos períodos uniformiza atributos físicos do solo e, em menor grau, os atributos químicos, os quais apresentam resultados semelhantes, independente da dose de palha. A aplicação de diferentes doses de $\mathrm{N}$ reduzem o $\mathrm{pH}$, os teores de $\mathrm{Ca}, \mathrm{Mg}$ e a saturação por bases no solo e aumentam a saturação por Al, para além da superfície do solo. Mesmo em sistema de semeadura direta, após longos períodos de aplicação de adubos nitrogenados $\left(40 \mathrm{~kg} \mathrm{ha}^{-1}\right)$, o uso superficial de calcário é necessário e capaz de elevar o pH e os teores de Ca no solo, em superfície e em subsuperfície.

\section{AGRADECIMENTOS}

Os autores agradecem à Fundação de Amparo à Pesquisa do estado de Minas Gerais (FAPEMIG), pelo auxílio financeiro, à Embrapa-Milho e Sorgo, pela instalação e condução do experimento e ao Conselho Nacional de Desenvolvimento Científico e Tecnológico (CNPq) pela concessão da bolsa de estudos ao primeiro autor. 


\section{REFERÊNCIAS}

ALVAREZ, V.H.V. et al. Interpretação dos resultados das análises de solos. In: RIBEIRO, A.C. et al. COMISSÃO DE FERTILIDADE DO SOLO DO ESTADO DE MINAS GERAIS - CFSEMG. Recomendação para o uso de corretivos e fertilizantes em Minas Gerais: $5^{\text {a }}$ Aproximação. Viçosa: MG, Embrapa/UFV/SBCS, 1999. Cap.5, p.25-32.

BEUTLER, A.N. et al. Agregação de latossolo vermelho distrófico típico relacionada com o manejo na região dos cerrados no Estado de Minas Gerais. Revista Brasileira de Ciência do Solo, Viçosa, v.25, n.1, p.129-136, 2001.

BAYER, C.; BERTOL, I. Características químicas de um Cambissolo Húmico afetadas por sistemas de preparo, com ênfase à matéria orgânica. Revista Brasileira de Ciência do Solo Viçosa, v.23, n.3, p.687-694, 1999.

BLEVINS, R.L. et al. Influence of no-tillage and nitrogen fertilization on certain soil properties after 5 years of continuous corn. Agronomy Journal, Madison, v.69, n.3, p.383-386, 1977.

CAIRES, E.F. et al. Alterações de características químicas do solo e resposta de soja ao calcário e gesso aplicados na superfície em sistema de cultivo sem preparo do solo. Revista Brasileira de Ciência do Solo, Viçosa, v.22, n.1, p.27-34, 1998.

CAMPOS, B.C. et al. Estabilidade estrutural de um Latossolo Vermelho-Escuro distrófico após sete anos de rotação de culturas e sistemas de manejo de solo. Revista Brasileira de Ciência do Solo, Campinas, v.19, n.1, p.121-126, 1995.

CASTRO FILHO, C. et al. Estabilidade dos agregados e sua relação com o teor de carbono orgânico num Latossolo Roxo distrófico, em função de sistemas de plantio, rotações de culturas e métodos de preparo de amostras. Revista Brasileira de Ciência do Solo, Viçosa, v.22, n.4, p.527-538, 1998.

EMPRESA BRASILEIRA DE PESQUISA AGROPECUÁRIA. Manual de métodos de análise de solo. 2.ed. Rio de Janeiro: Empresa Brasileira de Pesquisa Agropecuária, 1997. 212p.

FANCELli, A.L.; DOURADO NETO, D. Produção de milho. Guaíba: Agropecuária, 2000. 360p.

FRANCHINI, J.C. et al. Alterações na fertilidade do solo em sistemas de rotação de culturas em semeadura direta. Revista Brasileira de Ciência do Solo, Viçosa, v.24, n.2, p.459467, 2000.

FRANCHINI, J.C. et al. Potencial de extratos de resíduos vegetais na mobilização do calcário no solo por método biológico. Scientia Agricola, Piracicaba, v.58, n.2, p.357-360, 2001.
LOPES, A.S. Recomendações de calagem e adubação no sistema de plantio direto. In: COMISSÃO DE FERTILIDADE DO SOLO DO ESTADO DE MINAS GERAIS - CFSEMG. Recomendação para o uso de corretivos e fertilizantes em Minas Gerais: 5a Aproximação. Viçosa: Embrapa/UFV/ SBCS, 1999. Cap.13, p.93-98.

MIYAZAWA, M. et al. Effects of addition of crop residues on the leaching of $\mathrm{Ca}$ and $\mathrm{Mg}$ in Oxisols. In: INTERNATIONAL SYMPOSIUM ON PLANT-SOIL INTERACTIONS AT LOW pH, 4., 1996, Belo Horizonte. MG. Abstracts... Belo Horizonte: SBCS/Embrapa-Cerrados, 1996. p.8.

MUZILLI, O. Influência do sistema de plantio direto, comparado ao convencional sobre a fertilidade da camada arável do solo. Revista Brasileira de Ciência do Solo, Campinas, v.7, n.1, p.95-102, 1983.

PAIVA, P.J.R. Parâmetros de fertilidade de um solo do Paraná sob diferentes sistemas de manejo. 1990. 55f. Dissertação (Mestrado em Solos e Nutrição de Plantas) - Curso de Solos e Nutrição de Plantas, UFLA.

PAVAN, M.A.; OLIVEIRA, E.L. Manejo da acidez do solo. Londrina: IAPAR, 1997. 86p. (IAPAR. Circular, 95).

POTTKER, D.; BEN, J.R. Calagem para uma rotação de culturas no sistema de Plantio Direto. Revista Brasileira de Ciência do Solo, Viçosa, v.22, n.4, p.675-684, 1998.

SÁ, J.C.M. Manejo da fertilidade do solo no sistema plantio direto. In: SIQUEIRA, J.O et al. Inter-relação fertilidade, biologia do solo e nutrição do solo. Viçosa: SBCS, Lavras: UFLA/DCS, 1999. Cap.2, p.267-319.

SIDIRAS, N.; PAVAN, M.A. Influência do sistema de manejo do solo no seu nível de fertilidade. Revista Brasileira de Ciência do Solo, Campinas, v.9, n.3, p.249-254, 1985.

SILVA, F.C. Manual de análises químicas de solos, plantas e fertilizantes. Brasília: Empresa Brasileira de Pesquisa Agropecuária, 1999. 370p.

STALEY, T.E.; BOYER, D.G. Shot-term carbon, nitrogen and $\mathrm{pH}$ alterations in a hill-land Ultisol under maize silage relative to tillage method. Soil \& Tillage Research, Amsterdam, v.42, n.1/2, p.115-126, 1997.

SUMNER, M.E.; PAVAN, M.A. Alleviating soil acidity through organic matter management. In: SIMPÓSIO DE ROTAÇÃO SOJA/MILHO NO PLANTIO DIRETO, 1., 2000, PiracicabaSP. Anais... Piracicaba: POTAFOS, 2000. 1 CD. 